\title{
Estrutura e Programas de T\&D: o Caso das Empresas Públicas e Sociedades de Economia Mista do Estado de Minas Gerais
}

\author{
Jáder dos Reis Sampaio \\ Karlyson de Castro Tavares
}

\section{RESUMO}

No presente trabalho foram estudadas dez empresas públicas e sociedades de economia mista da esfera do Estado de Minas Gerais, de setores variados da economia, nas quais se analisaram indicadores de demonstrativos financeiros e se realizaram entrevistas semi-estruturadas com responsáveis pela área de treinamento e desenvolvimento de recursos humanos. Construiu-se uma escala de estrutura e programas de treinamento e desenvolvimento, com alto índice de fidedignidade. Observou-se a existência de três grupos distintos de empresas com estruturas e programas diversos e uma mudança nos padrões de treinamento e desenvolvimento de empresas públicas brasileiras, encontrados na literatura. Constatou-se a associação entre a complexidade das estruturas e programas e duas variáveis externas: a implantação de novas tecnologias de gestão e o perfil de escolaridade dos empregados.

Palavras-chaves: administração pública; treinamento e desenvolvimento; gestão de pessoas.

\begin{abstract}
It was studied the structure and programs of training and development areas from public companies in Minas Gerais, Brazil. In order to compare the areas, it was developed a scale to measure the existence of programs and characteristics of structure of training and development. The first analysis of this scale's validity found a Cronbach's alpha of 0,9 . The results identified three different groups of companies. The difference of these groups was associated with two external variables: the use of new administrative technologies and the education of the employees.
\end{abstract}

Key words: public management; training and development; human resources management. 


\section{INTRODUÇÃO}

As políticas e práticas de pessoal são influenciadas pelas contingências que o ambiente de negócios, político, social e cultural lhe apresentam. A compreensão da qualificação dos servidores de empresas públicas e similares demanda, inicialmente, que se identifiquem as principais mudanças por que passaram as organizações brasileiras recentemente.

Nos anos 90, com as políticas econômicas de maior abertura do mercado brasileiro às empresas estrangeiras, a facilidade de importação de produtos e tecnologia e a redução acentuada do processo inflacionário, verificaram-se inúmeras mudanças nas empresas que operam em nosso país, quer sejam públicas ou privadas. Algumas das mudanças se efetuaram em nível administrativo. As áreas de produção, mercadologia, logística e a estruturação das empresas implementaram novos programas, políticas e concepções. Estas mudanças não se efetuaram de forma homogênea em todas as empresas ou setores da economia, não sendo viável tentar simplificar ou reduzir nossa análise.

A década iniciou-se sob a influência dos programas de qualidade total, incentivados pelo governo federal na gestão Collor de Mello. Originalmente, tratava-se de mudanças de práticas de produção, sob uma lógica de participação colaborativa dos empregados, enriquecimento de tarefas, melhora continuada de produtos, processos e serviços e agregação de etapas produtivas como o controle de qualidade e a manutenção ao processo de montagem ou equivalente. Qualidade total tornou-se um modismo, ocupando grande número de páginas da imprensa especializada e um grande número de horas de consultoria por parte das organizações. Ela atingiu primeiramente a iniciativa privada e o segmento de produção para o mercado do setor público. A lógica de gestão de pessoas atrelada à qualidade total propõe políticas de manutenção, qualificação e participação, mas em muitas das empresas ligadas ao programa no Brasil, não lhe foi dispensada a devida atenção. Passado o modismo, muitas das práticas de qualidade se encontram ambientadas no cenário industrial, um pouco menos no cenário de prestação de serviços e há esforços de aplicação em organizações como hospitais e escolas.

Em uma pesquisa com empresas que utilizaram qualidade total, autores argumentaram em defesa de uma área de treinamento e desenvolvimento (T\&D) estruturada e plena de programas, fazendo uma sonora afirmação: "mais importante ainda, nenhuma empresa mal colocada nos critérios de treinamento obteve 
uma boa pontuação para a sua gestão de qualidade" (Rabelo, Bresciani e Oliveira, 1995, p. 19).

As políticas de qualidade se fizeram acompanhar pelo interesse de grande número de organizações em obter certificações de qualidade, como as normas ISO que, entre outras propostas, exigiam um registro acurado de todos os processos organizacionais, incluindo aí os processos de T\&D, e demandando a existência de programas como os de necessidades de treinamento.

No início da década de 90 foram implementados alguns programas nas empresas de médio e grande porte, as quais modificaram a sua estrutura. Um dos programas muito implementados no primeiro qüinqüênio foi o de terceirização, que em essência significa transferir atividades até então realizadas pelas empresas para prestadoras de serviço, com o objetivo de focalizar as atividades do corpo administrativo na atividade-fim da empresa. No Brasil, algumas empresas vislumbraram a possibilidade de reduzir custos com esta operação. No início deste movimento, as atividades mais terceirizadas foram as de serviços gerais, restaurante e segurança, o que promoveu o incentivo para a criação de novas agências de prestação de serviços, assim como o crescimento das agências que já operavam no mercado.

Outro modismo que atingiu as empresas nesta década foi o chamado downsizing que é uma estratégia de redução de quadros e níveis hierárquicos das empresas, adaptando-as a um cenário de redução da demanda. No cenário americano e europeu, esta técnica foi motivada pelo desenvolvimento acentuado da tecnologia de informação (TI) e das telecomunicações. O impacto da TI nas estruturas das empresas tornou-se ainda mais efetivo com a proposição da reengenharia, por Michael Hammer e colaboradores, que aportou em nosso ambiente de negócios no meio da década. Preocupado inicialmente em utilizar em grau máximo as possibilidades da informática nas empresas, ele propôs a substituição da análise estrutural das empresas por uma análise focalizada em processos, o que permite a clara identificação da eliminação de etapas de trabalho e a redução de postos de especialidades; mas, em contrapartida, exige a multiqualificação de empregados para realizar atividades mais complexas com o auxílio de computadores e outros dispositivos de informática e, por conseqüência, a redução drástica do tempo necessário para a realização de certos procedimentos.

A redução de quadros, por motivos diversos, incluindo aí a reforma administrativa do Estado, gerou uma grande demanda por recolocação de pessoal e outplacement, que teve implicações nas áreas de recursos humanos e na consolidação de pequenas empresas de colocação de pessoal, que se tornariam constantes no cotidiano das grandes e médias empresas. 
Com a competitividade e a entrada de novas empresas concorrentes no ambiente de negócios, o pensamento estratégico foi valorizado na gestão das empresas brasileiras. Como resultado, vimos o reposicionamento das empresas diante do mercado, a busca de identificação de competências essenciais por elas, e a ênfase no estabelecimento de metas e objetivos a partir de análises ambientais.

Outro tema influente no cotidiano das organizações brasileiras diz respeito à globalização e aos avanços na constituição de uma área de livre comércio no cone sul da América Latina, o Mercosul.

Os impactos observados nas práticas de recursos humanos, de forma geral, foram a necessidade de mudarem-se programas até então considerados satisfatórios, como a remuneração, por exemplo, para atender-se às demandas de flexibilidade de processos e produtos nas organizações, assim como para coadjuvar os esforços de atingir os propósitos definidos no jogo estratégico. Outro impacto marcante foi a demanda por empregados com melhor nível de escolaridade, capacidade de trabalho em equipes e comprometimento organizacional, capazes de se envolver no jogo empresarial com idéias e ações que marcam a diferença na competição.

Formadores de opinião, em pesquisa realizada pelo PROGEP/USP, consideram que as atividades de $T \& D$ se tornaram mais relevantes no ambiente atual das organizações brasileiras, encontrando-se no topo da lista.

Considerando-se a centralidade de T\&D nas práticas de gestão de pessoas, realizou-se uma pesquisa em empresas públicas e sociedades de economia mista do Estado de Minas Gerais. Foram construídos indicadores do ambiente econômico-social e financeiros, bem como dos programas e estruturas das áreas de T\&D existentes nestas organizações. As principais fontes consultadas foram dados transcritos de entrevistas e análise de demonstrativos financeiros. Empregaram-se métodos de construção de escalas e de estatística multivariada para o tratamento dos dados obtidos ${ }^{(1)}$.

Observou-se uma pluralidade de perfis neste segmento empresarial, com ofertas muito distintas de programas e estruturas de recursos humanos, relacionados ao emprego de novas tecnologias empresariais e escolaridade dos empregados. Os dados obtidos apontam mudanças marcantes nas práticas deste segmento, como veremos a seguir. 


\section{Teoria, Estruturas e Programas de T\&D}

Por treinamento os especialistas geralmente entendem as atividades de qualificação voltadas a preparar o empregado para exercer o cargo ou espaço ocupacional para o qual foi contratado. Dependendo do cargo, o treinamento pressupõe a existência prévia de uma formação profissional, que seria de âmbito mais acadêmico, podendo estar vinculada à obtenção de algum tipo de licença para o exercício da profissão, ou à obtenção de títulos, seja no ensino fundamental, médio, superior ou na pós-graduação.

As atividades de treinamento geralmente são classificadas como técnicas ou comportamentais. Por atividades técnicas, ou simplesmente treinamento técnico, entendem-se os esforços de complementar a formação profissional, com conhecimentos e práticas ligados a essa, que não foram contemplados durante a formação profissional, por serem muito específicos ao cargo ou por outra razão. Por treinamento comportamental entende-se qualquer atividade voltada ao preparo do profissional para o relacionamento interpessoal no ambiente de trabalho.

Estão surgindo novos termos, como educação corporativa, a pleitear a totalidade dos termos existentes incorporados dos novos processos e métodos educacionais decorrentes do desenvolvimento tecnológico, como o ensino a distância, $\mathrm{o}$ emprego de microcomputadores e da Internet. Cabe ao tempo e aos profissionais da área decidirem se estes termos serão incorporados ao jargão ou se serão conhecidos como modismos do final dos anos 90 .

Mantém-se neste trabalho a terminologia tradicional, que distingue treinamento (cargo), desenvolvimento (carreira), educação profissional (profissão) e educação (vida e cidadania). Entende-se também que T\&D pode estar a serviço de diferentes políticas e estratégias de pessoal.

Uma distinção já incorporada ao jargão dos profissionais da área envolve a distinção entre os treinamentos out of the job, formais, realizados em sala de aula ou em laboratório, geralmente com abordagem instrucional, cognitiva ou vivencial, e os treinamentos on the job, treinamentos em serviço, realizados nos postos de trabalho, de conteúdo geralmente profissionalizante. Os treinamentos em serviço ganharam notoriedade nas empresas mais recentemente, com as críticas e propostas alternativas ao taylorismo como método de organização do trabalho.

Robbins (1999) identifica como práticas próprias desta categoria a rotação de cargos, onde se capacitam empregados para ocupar cargos diferentes de mes- 
mo nível hierárquico nas organizações, os estágios e programas de trainees, onde os treinandos trabalham com supervisão e acompanhamento.

Entendemos que a mera delegação a um empregado da capacitação de um treinando não pode ser entendida como treinamento em serviço. A idéia de treinamento pressupõe certa organização prévia, acompanhamento e avaliação de resultados que, neste caso, seria o desenvolvimento de habilidades técnicas ou competências.

Os estágios, no cenário brasileiro, são programas de exercício orientado da profissão, regulamentados pela Lei 6.497 de 1977 e pelo Decreto-Lei 87.497 de 1992, onde se determina a ausência de vínculo empregatício com a empresa, que é isenta das obrigações trabalhistas, e que tem por finalidade o complemento das atividades de ensino, qualificando alunos com conhecimentos técnicos específicos à sua área de formação, seja esta em qualquer dos níveis de ensino (fundamental, médio ou superior).

Os programas de trainee são voltados a uma preparação generalista de profissionais recém-admitidos em empresas com políticas de manutenção de recursos humanos. Apesar de terem sido situados nesta categoria, eles mesclam estratégias de treinamento em serviço com as de treinamento out of the job ou convencional. Além das instruções formais sobre temas específicos, que são articuladas com a rotação de cargos, eles incorporam a realização de projetos no ambiente de trabalho e programas de tutoria, além da avaliação sistemática dos trainees e do programa em si.

Os programas de treinamento introdutório têm por objetivo a ambientação do empregado recém-admitido no ambiente de trabalho, ou seja, a apresentação de colegas, chefes, estrutura e negócio da organização, processos produtivos, normas, direitos, benefícios, e alguns programas básicos de treinamento, como segurança no trabalho, introdução à qualidade total e mesmo o seu preparo inicial para o exercício do cargo.

Encontram-se programas calcados apenas em uma entrevista rápida com a área de admissão e algumas conferências, e programas elaborados, com visitas técnicas, exibição de vídeos e práticas de tutoria associadas à programação.

Motomura (1980, p. 146) define simulação como "uma experiência, um ensaio no qual se procura representar com semelhança, uma determinada situação, o que acontece ou poderia acontecer na vida real". Neste conceito amplo, cabem múltiplas técnicas de simulação. Ramos (1980) relaciona os dramas, como psicodrama e sociodrama; desempenho de papéis (role-playing); estudos de casos; bandejas de decisão e jogos, entre eles os jogos de empresa. 
É inegável o caráter lúdico dos jogos, que torna prazerosa a experiência de aprender coletivamente, o que gerou uma discussão sobre o seu papel nos programas de treinamento. Seria um artifício para o relaxamento dos participantes, simplesmente, ou teria caráter de promoção da aprendizagem? O tema é polêmico, mesmo porque há profissionais que empregam os jogos mais pelo seu impacto nas avaliações de reação, que por uma preocupação com os conteúdos que nele seriam abordados. Sauaia (1997) advoga que os jogos de empresa promovem "aprendizagem com satisfação".

Os programas de gestão de $\mathbf{T} \& \mathbf{D}$, embora possam ser constituídos de forma metodológica diversa, basicamente envolvem quatro ações básicas, como se vê na Figura 1.

\section{Figura 1: Função Gerencial de T\&D}

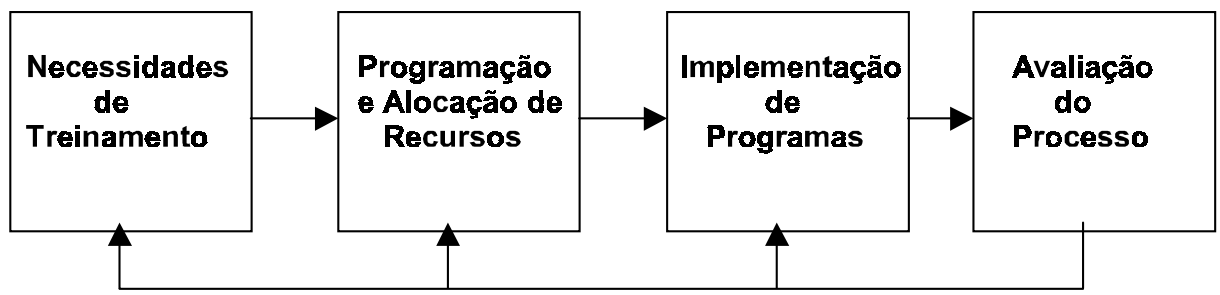

Com isto consideram-se as decisões de identificação e determinação de necessidades de treinamento; programação, entendida não apenas como criação de cardápios de curso ou cronogramas, mas como decisões referentes aos perfis e oportunidade dos diferentes programas ligados a T\&D; alocação de recursos; implementação e avaliação do processo realizado como decisões de gestão e passa-se a decidir sobre as competências a serem atribuídas a órgãos de staff e de linha no contexto organizacional.

Os programas de requalificação ou reconversão de mão-de-obra são fruto da aceleração das mudanças no mundo do trabalho brasileiro dos anos 90 . Este tipo de programa busca preparar empregados de cargos extintos por diversas razões, para ocupar outras posições na organização ou no mercado de trabalho.

A implantação de programas de qualidade total gerou uma reflexão específica por parte dos principais consultores envolvidos na sua aplicação sobre o treinamento. Juran (1990) considera que os treinamentos visam à mudança da cultura organizacional, devem ser realizados por todos os membros da organização e esta deve municiá-los com um corpo de conhecimentos coerente e suficiente. Segundo este autor, uma vez decidida a implantação da gestão pela qualidade total, os programas devem ser impostos pela alta gerência, sendo realizados 
top down, ou seja, primeiramente pela alta gerência, depois pela média, especialistas e depois pelos diferentes níveis operacionais. A sua programação envolve temas e cursos diversificados, alguns voltados a especialidades, o que demanda uma organização de conteúdos e públicos. Juran (1990) considera importantes os seguintes conteúdos:

. definição da qualidade e seu papel nos objetivos empresariais;

. planejamento, controle e melhoramento da qualidade;

- aplicação da qualidade em diferentes funções organizacionais (finanças, marketing e desenvolvimento do produto, por exemplo);

. ferramentas e técnicas da qualidade.

Ele entende que a organização e implementação desses programas deve ser feita por uma força tarefa da organização, composta por gerentes de alto nível, e não pela área de T\&D.

A aprendizagem organizacional, assim como a aprendizagem individual, constitui-se num processo de mudança por meio da aquisição de novos conhecimentos, soluções de problemas e insights. Fleury e Fleury (1995) consideram que o processo de aprendizagem organizacional compreende mudanças de comportamento, influências de fatores sociais, experiências passadas, circulação de conhecimento etc.

Do ponto de vista dos recursos humanos, as empresas envolvidas neste processo têm procurado mudanças em relação a estas políticas, elaborando novas práticas que sustentem e impulsionem os processos de aprendizagem.

Nas organizações qualificantes, a capacitação e desenvolvimento dos trabalhadores surge como estratégia fundamental para uma mudança organizacional. Assim, as empresas têm aumentado o seu investimento em treinamentos na busca de maior capacitação, não apenas de nível gerencial, mas também de níveis operacionais. A preocupação com a capacitação dos trabalhadores não se restringe a treinamentos técnicos ou comportamentais. Outras estratégias são utilizadas, como a melhoria no sistema de comunicação interna, círculos de controle de qualidade (CCQ), caixas de sugestões, avaliação de desempenho individual, programas de qualidade total, planos de carreira e remuneração e outros, sendo esta prática resultado de um planejamento de recursos humanos, de acordo com o planejamento da empresa, na busca de uma mudança da cultura organizacional.

Outro tema emergente, resultante da descentralização nas práticas de recursos humanos sobre a organização de $\mathrm{T} \& \mathrm{D}$, é a sua constituição sob a forma de unidade de negócios. Neste arranjo, as áreas de T\&D se tornam um negócio 
dentro da organização, com orçamento restrito, visto que os recursos a serem investidos em treinamento são geridos pelas áreas-fins, que passam a poder encomendá-los internamente ou procurar serviços de outras empresas.

Este formato de agência que se dá à área de $T \& D$ permite transformar os cursos e tecnologias de treinamento em produtos da organização, a serem oferecidos a clientes, parceiros e concorrentes, o que caracteriza essas atividades como negócio da organização. A agência tem como atribuição a organização de programas corporativos, que vão atingir as diversas unidades de negócios, ocupando, portanto, um papel mais estratégico e deixando as necessidades locais a cargo das áreas-fins. O sucesso ou insucesso financeiro da área passa a ser um indicador de resultados a ser assumido pela direção da organização.

Um terceiro movimento em T\&D é o emprego de coachs, que são instrutores particulares, contratados por executivos, para desenvolverem as suas habilidades (skills) e conhecimentos técnicos. Há diferentes formas de se fazer coaching, que pode durar períodos de tempo curtos, um mês ou menos, ou longos, um ano ou mais. Thach e Heinselman (1999) afirmam que este tipo de programa tinha por público principal os executivos com problemas de carreira, mas agora têm por público principal os executivos em ascensão e os top leaders. Os coachs são preferencialmente profissionais do mesmo ramo de atuação do executivo, com conhecimento de instrumentos de avaliação $360^{\circ}$, conhecimento de desenvolvimento de profissionais, com capacidade de entender o ambiente organizacional, com habilidade de confrontar e dar suporte e são pessoas de confiança, de quem se pode esperar confidencialidade.

Os centros de aprendizagem empresarial (corporate learning centre) são espaços de aprendizagem criados em organizações de trabalho que possibilitam a realização de programas de ensino com o emprego de novas tecnologias. Malone (1997) os difere dos centros de treinamento tradicionais, por focalizarem os seus programas em processos de ensino individual ou em duplas, e não coletivo (turmas), flexível, regido pelo ritmo individual, com a mediação de um coordenador geral, e não de um instrutor ou especialista, não ameaçador e de interação limitada. Ele os associa à criação de uma cultura de aprendizagem dentro da organização, o que os aproxima da noção de learning organization, ou empresa que aprende.

O termo universidades corporativas vem sendo utilizado crescentemente por empresas americanas e brasileiras para designar o conjunto de mudanças implementadas na tradicional área de treinamento e desenvolvimento de recursos humanos. Não se trata de criação de universidades no setting empresarial, nem de criação de cursos de graduação e pós-graduação de âmbito restrito a uma empresa, muito menos da associação das áreas de pesquisa e desenvolvi- 
mento às áreas de $\mathrm{T} \& \mathrm{D}$, mas do emprego do termo como metáfora que designe o que Meister (1999, p. 263) define como "guarda-chuva estratégico para o desenvolvimento e educação de funcionários, clientes e fornecedores, com o objetivo de atender às estratégias empresariais de uma organização".

Meister (1999) propõe a construção de conteúdos de currículos com base nos seguintes tópicos: cidadania corporativa, onde se discutiria valores, cultura, história e tradições da empresa; estrutura contextual, onde se analisariam clientes, fornecedores, concorrentes, tendências do setor, estratégias empresariais e melhores práticas e, finalmente, as competências básicas do ambiente de negócios.

Nos Estados Unidos, já se encontram cerca de duas mil organizações que se autodenominam universidades corporativas, envolvendo cerca de $40 \%$ das quinhentas maiores empresas do país. No Brasil, Eboli (1999) já pesquisou algumas dezenas de grandes empresas que adotaram a terminologia e alguns dos conjuntos de propostas associados a elas.

Que tipo de estruturas e programas de T\&D apresentam as empresas públicas? Que problemas elas enfrentam? No final da década de 70, Motta (1981) realizou uma pesquisa de âmbito nacional sobre os programas de treinamento e desenvolvimento gerencial realizados por empresas estatais. Ele concluiu que a atividade de treinamento era "gerida por um setor especializado dentro de um departamento maior de recursos humanos" (Motta, 1981, p. 125), que se relacionava com o resto da organização mediante a oferta de cursos, levantamento de necessidades de treinamento e, com menor freqüência, pela avaliação do treinamento. Dificilmente se encontrava integração entre esses programas e os objetivos e planos da empresa; as próprias empresas raramente operacionalizavam seus planos.

A maioria dos setores funcionava como centros de triagem de demandas internas e ofertas externas; tinham dificuldade em acompanhar as mudanças dos conhecimentos, tornando-se obsoletas e repetitivas. Nas grandes empresas públicas federais encontravam-se iniciativas de formação interna, acompanhadas de grandes centros de treinamento ou escolas.

Este arranjo de $T \& D$ favoreceu modismos e receitas rápidas, pulverizou a aplicação de recursos financeiros e evitou parcerias com universidades e centros de conhecimentos. As áreas de T\&D eram dirigidas por pedagogos e psicólogos, mas não contavam com adesão imediata dos executivos do primeiro escalão e tinham por público gerentes indicados por políticos externos e não selecionados por critérios técnicos. Os seus técnicos levantavam necessidades por meio de questionários; mas apenas em grandes empresas levantam necessidades de nível 
individual e organizacional. Investia-se em programas de desenvolvimento gerencial, com excesso de conteúdos psicológicos, e as suas atividades não se achavam vinculadas aos planos de carreira.

Outro estudo que influenciou a presente pesquisa foi realizado pela Fundação João Pinheiro (1996), que analisou a cultura organizacional dos órgãos públicos do poder executivo do Estado de Minas Gerais. Neste trabalho, observaram-se as representações sociais dos servidores públicos lotados nas organizações, que apresentaram uma visão de si mesmos e das organizações onde trabalhavam distintas da imagem construída em torno do servidor público pela sociedade brasileira. Os pesquisadores da Fundação João Pinheiro analisaram 5.066 questionários preenchidos por servidores públicos do poder executivo mineiro. Entre outros resultados, constataram que a subcultura mais proeminente considera as organizações onde se trabalha bem estruturadas, planejadas e preocupadas com o aumento de produtividade. $\mathrm{O}$ servidor não se considera refratário às novas tecnologias, apresenta atitude positiva com relação às mudanças e considera 0 processo decisório lento, verticalizado, pouco técnico e imposto de cima para baixo. Não foi encontrada diferença significativa entre as subculturas de órgãos da administração direta e indireta no Estado.

"Com relação às políticas de recursos humanos do Estado, o servidor mostrase favorável à eliminação dos resíduos do clientelismo, reconhece a realização de alguns programas, valoriza o concurso público, e afirma existir uma política bem definida. Porém têm opiniões divergentes sobre o treinamento dos servidores públicos e o reconhecimento de seus resultados, e considera que a política implementada pelo Estado seja suficiente para promover a satisfação no trabalho, a dedicação e o bom desempenho" (Fundação João Pinheiro, 1996, p. 63). Os autores percebiam a existência de diferentes grupos de respostas e inferiam a existência de diferenças com relação à eficiência e estruturação dos órgãos.

\section{Metodologia da Pesquisa}

Escolhendo-se a classificação de Gil (1987) como referente, a presente pesquisa se caracteriza, quanto ao objetivo, como pesquisa explicativa e, quanto ao delineamento, como ex-post-facto.

O universo da presente pesquisa são as empresas públicas e sociedades de economia mista do Estado de Minas Gerais, que na época da coleta de dados somavam 20 organizações. Apesar de não poder ser considerada aleatória, se estratificarmos o universo em análise, veremos que as empresas participantes 
cobrem os mais diferentes estratos dele, dada a diversidade dos seus perfis e de atividades-fins. Foram estudadas 8 sociedades de economia mista e 2 empresas públicas. A partir das comparações entre as características da amostra e do universo, entendemos que os resultados podem ser generalizados para o universo, com pequena possibilidade de alterações significativas deles.

As análises e discussões da presente pesquisa repousam sobre duas fontes de informação: entrevistas semi-estruturadas e análise de demonstrativos financeiros das organizações.

Mesclaram-se técnicas de análise qualitativa à análise quantitativa. Empregou-se a regressão múltipla, método stepwise, com os valores default de entrada e retirada de variáveis do modelo. Para fins de comparação entre as empresas desenvolveu-se uma escala de estrutura e programas de treinamento e desenvolvimento (EEPT\&D). Os itens componentes da presente escala foram extraídos do roteiro de entrevistas e a atribuição de pontos que se thes conferiu foi realizada a partir dos dados fornecidos. A presente escala não pode ser considerada uma escala de opiniões, porquanto a equipe de pesquisa escolheu indicadores que apontam a presença/ausência de programas e/ou estruturas organizacionais ligadas à realização de $\mathrm{T} \& \mathrm{D}$ em organizações do serviço público. Os indicadores, que possuem igual peso no cômputo geral da escala, se acham relacionados na Figura 1.

A presente escala foi submetida a um exame da sua fidedignidade (reliability), empregando-se o alfa de Cronbach; o valor obtido foi $\mathbf{0 , 9 0}$, o que indica alta fidedignidade da escala construída.

Os estudos de caso têm por principal problema o âmbito adotado para a generalização dos resultados. Entendemos que os resultados encontrados são representativos da realidade do Estado de Minas Gerais, e que têm valor duvidoso na análise das empresas públicas de outros Estados e da esfera federal. A metodologia desenvolvida, entretanto, com pequenos ajustes, mostrou-se aplicável em diferentes realidades, assim como as categorias descritivas das estruturas e programas de $\mathrm{T} \& \mathrm{D}$.

\section{Estrutura Administrativa e Programas de T\&D de Empresas Públicas e Sociedades de Economia Mista no Estado de Minas Gerais}

As empresas estudadas atuam em áreas diversas, como estas: fomento, energia, prestação de serviços, desenvolvimento industrial, administração de bens públicos 
etc. O seu desempenho financeiro foi verificado com base em dois indicadores: $\mathrm{o}$ ativo circulante e a taxa de retorno sobre o ativo total. Seis das empresas possuíam seu ativo circulante numa faixa entre $\mathrm{R} \$ 1,4$ e $\mathrm{R} \$ 10$ milhões, enquanto o ativo das outras quatro variava entre $\mathrm{R} \$ 25$ e $\mathrm{R} \$ 600$ milhões. O retorno sobre o ativo total destas empresas é o que se segue.

\section{Tabela 1: Taxa de Retorno sobre o Ativo Total das Organizações Estudadas}

\begin{tabular}{l|c}
\hline Faixas de ROA & No. de Empresas \\
\hline De $17 \%$ a $1,5 \%$ negativos & 4 \\
Próximo a $0 \%$ & 2 \\
De $2 \%$ a $18 \%$ & 4 \\
\hline Fonte: dados da pesquisa.
\end{tabular}

Apontamos anteriormente a tendência de aumentar-se a competitividade entre empresas e também o interesse do Estado, no âmbito federal, em privatizar as empresas públicas e sociedades de economia mista. Cinco das organizações visitadas afirmam não possuírem concorrentes no mercado; a sua justificativa geralmente se baseia no desinteresse do setor privado em atuar no seu segmento. Seis das organizações visitadas não consideram relevante a possibilidade da sua privatização e, por conseqüência, afirmam não terem realizado nenhum esforço gerencial no sentido de antecipar-se ou preparar-se para tal.

Todas as empresas investiram, de algum modo, em tecnologia da informação nos últimos anos, mas de forma muito desigual. Alguns entrevistados ilustram as suas posições com exemplos triviais de automação de escritórios, enquanto outros apontam sistemas informatizados complexos, como o SAP R3, e a alteração significativa de rotinas de T\&D em função da implantação de Intranet e programas estruturados.

Seis das organizações visitadas afirmam ter implementado novas tecnologias gerenciais como qualidade total e reengenharia. O mesmo número afirma fazer planejamento estratégico, e não apenas a prática de orçamentos. Sete das empresas afirmam possuir programas de qualidade de vida no trabalho, mas estes se caracterizam, em sua grande maioria, como iniciativas isoladas, palestras, e programas "fora do local de trabalho".

Paradoxalmente, apesar das mudanças apontadas, seis das empresas afirmam que não houve uma mudança significativa de perfil dos empregados nos últimos anos. Esta situação pode ser explicada por dois motivos: a superqualificação dos empregados, característica dos órgãos públicos, e as mudanças gerenciais foca- 
lizadas, que atingem apenas as áreas administrativas, mas não chegam a ser implementadas nas instâncias onde se realiza a sua atividade-fim.

Verificamos que a escolaridade dos empregados é superior à média das empresas privadas brasileiras. Em sete dos participantes mais de $90 \%$ dos empregados possui mais que o primeiro grau, e nos outros três a taxa de conclusão do primeiro grau varia de $50 \%$ a $80 \%$ do efetivo.

Apesar de a política de terceirização ser aplicada por grande parte das organizações visitadas, atingindo setores como serviços gerais, segurança, transporte e prestação de serviços, o número de empregados terceirizados é relativamente baixo, são 34 empregados em média. Esses empregados, na maioria das organizações visitadas, não estão incluídos nas práticas de treinamento e desenvolvimento das empresas.

As estruturas e programas de $T \& D$ apresentam diferenças significativas entre as organizações visitadas. A existência de uma área de $T \& D$ ou similar (universidade corporativa, por exemplo) na estrutura organizacional segue a seguinte distribuição: seis das empresas não posuem uma área de $T \& D$, duas possuem de 4 a 6 pessoas lotadas na área e as duas outras possuem respectivamente 14 e 30 pessoas voltadas à área.

Na maioria dos casos em que não há área de T\&D ou equivalente, esta nunca existiu na organização; em algumas destas, não há uma área de recursos humanos estruturada ou similar, sendo atribuição de um gerente administrativo-financeiro a realização de todas as atividades próprias da área de pessoal e recursos humanos, além de outros encargos. Encontramos redução de quadros de T\&D em algumas das organizações que possuíam esta área, mas sem a sua extinção ou terceirização completa das suas atribuições, como desejam alguns autores, influenciados pelo modismo da descentralização.

Outra informação importante refere-se à alocação de recursos para a área de T\&D. Entendemos que a existência de recursos alocados é a garantia mínima da efetivação de programas da área, sejam estes recursos administrados pela área de T\&D ou pelas áreas-clientes, que o empregariam segundo as próprias demandas e necessidades. A inexistência de recursos orçados ou, pelo menos, planejados para $T \& D$ deixa os programas ao arbítrio de gerentes e diretores da organização, o que permite certo clientelismo e outro tanto de casuísmo nas ações de qualificação.

Quanto aos investimentos em treinamento, duas empresas participantes admitiram não possuir verba alocada para esta atividade; quatro não forneceram esta informação; as quatro restantes forneceram valores que variaram entre $\mathrm{R} \$ 285,00$ e $\mathrm{R} \$ 1.850,00$ por empregado por ano. 
Com a aplicação da escala de estrutura administrativa e programas de T\&D, obtivemos a seguinte distribuição das organizações estudadas.

\section{Tabela 2: Desempenho das Organizações na EEPT\&D}

\begin{tabular}{l|c}
\hline Resultado Obtido & No. Empresas \\
\hline 0 a 3 pontos & 3 \\
8 a 10 pontos & 3 \\
12 a 14 pontos & 4 \\
\hline Fonte: dados da pesquisa.
\end{tabular}

Agrupamos, portanto, as organizações participantes em três grupos distintos. A diferença entre os grupos é estatisticamente significativa. Empregando-se ANOVA, obtivemos uma probabilidade $\mathrm{F}>0,001 \%$.

Os resultados brutos de freqüência de cada item da escala podem ser visualizados na Figura 2.

Figura 2: Estrutura Administrativa e Programas de T\&D de Empresas Públicas e Sociedades de Economia Mista de Minas Gerais

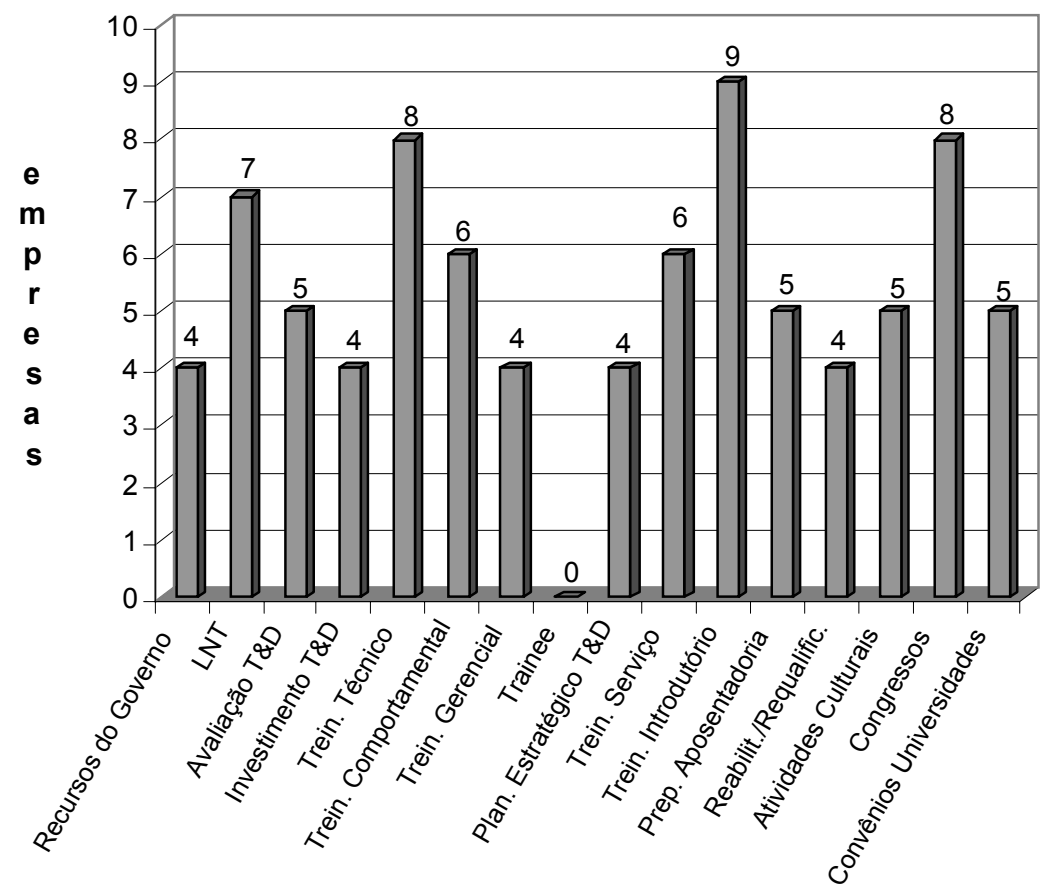

Fonte: dados da pesquisa. 
Como se pode constatar, os programas mais incidentes são o treinamento introdutório, o incentivo para participação em congressos ou seminários, a existência de programas de treinamento técnico e os programas de necessidades de treinamento; mas, uma análise de conteúdo das entrevistas nos aponta alguns limites e variações internas a serem considerados por estes indicadores, que discutimos no relatório final, e que excluímos deste artigo.

Quatro das empresas relatam haver relações entre o planejamento estratégico e T\&D; mas, nestes casos, o papel de T\&D parece ser reativo na formulação das estratégias e não parte integrante delas. Uma das empresas do grupo 1 chegou a considerar ultrapassados "os programas de planejamento estratégico", mostrando desconhecimento do movimento atual na administração brasileira, que se preocupa com a identificação de vantagens competitivas futuras e com a chamada gestão estratégica.

No extremo oposto do gráfico, vê-se a inexistência de programas de trainees, seguida da existência dos seguintes itens em apenas quatro das empresas visitadas: uso de recursos oficiais do governo em T\&D; registros com gastos em $\mathrm{T} \& \mathrm{D}$, para fins gerenciais; incidência de programas de desenvolvimento gerencial; associação entre planejamento estratégico e T\&D; e programas de reabilitação/requalificação profissional.

Sobre o futuro da área, uma das organizações estudadas destacou o programa de "desenvolvimento de equipes", a construção de um ambiente que permita inovação como atividades em curso ou a serem desenvolvidas e o investimento em tecnologia da informação para "atualização das bases de dados disponíveis na empresa". Outra organização, também do grupo 3, mostrou a intenção de transformar-se em uma espécie de unidade de negócios, oferecendo os seus produtos ao mercado de outras empresas similares, entre outras ações consistentes com o modelo.

As empresas mal situadas na escala de forma geral não se pronunciaram ou apontaram para a direção da responsabilidade de trazer algo novo, colocando-se em posição de executores, sem espaço para planejar e propor. As demais têm vistas e propostas para as suas necessidades atuais, como a disponibilização de pessoas na equipe, que permitam aos técnicos da área empreenderem novos programas, implantação de programa de ginástica na empresa, prospecção de recursos do Fundo de Amparo ao Trabalhador, desenvolvimento de novos programas comportamentais e operacionais, destinar recursos para a pesquisa e realização de mestrado interinstitucional.

Não houve referência à criação de universidades corporativas, à montagem de algo que se assemelhasse a um centro de aprendizagem empresarial, coaching, 
com a ressalva de ter-se encontrado algo similar em uma das empresas visitadas, à gestão de competências ou aprendizagem organizacional.

Quanto aos parceiros, o Sistema S (SENAI, SENAC, SEBRAE etc.) e a Federação das Indústrias do Estado de Minas Gerais estão bem representados em cursos de curta duração para o nível operacional, administrativo e de informática. Neste segmento eles se constituem como top of mind. Há uma referência ao CEFET/MG. Todos os entrevistados se referem aos folders que recebem de agências particulares; encaminham-nos e realizam treinamento com elas, mas não se recordam espontâneamente dos seus nomes. Quanto ao Sistema S, cabe uma ressalva, já que em certo número das organizações visitadas, parte do seu convênio constitui uma espécie de verba lotada em T\&D, e as empresas de alguns dos entrevistados participam de seus órgãos colegiados, o que acaba por consolidar esta parceria.

No segmento de pós-graduação lato sensu, as instituições top of mind são o IBMEC, a Fundação Getúlio Vargas e a Fundação Dom Cabral. Em um segundo plano, se referem à UNA e ao CEPEAD/UFMG, apesar do destaque que uma das empresas deu a este último. O Unicentro Newton Paiva foi identificado por um dos entrevistados como um local de obtenção de estagiários.

Quanto às agências do governo do Estado, a Fundação João Pinheiro é percebida como instituto de pesquisas e "fonte de dados", local de realização de seminários e agência administradora de recursos do FAT, por alguns poucos entrevistados, mas não como centro de pós-graduação ou agência capaz de fornecer cursos de curta duração sob encomenda.

Os programas de pós-graduação stricto sensu não parecem alvo das políticas de qualificação das empresas visitadas, com exceção de uma delas.

Esta pesquisa buscou focalizar a relação entre as práticas adotadas de T\&D e o ambiente externo das empresas públicas. Empregou-se, para tal, a regressão múltipla stepwise, conforme descrito na seção de metodologia, obtendo-se um modelo com poder de explicação alto $\left(\mathrm{r}^{2}\right.$ ajustado $\left.=0,89\right)$. $\mathrm{O}$ resultado obtido encontra-se na Figura 3.

Observa-se que a existência de estrutura e programas de T\&D está fortemente associada ao emprego de novas tecnologias gerenciais e às altas taxas de escolaridade dos empregados. É expressivo neste resultado a seguinte associação: as empresas públicas que não modificaram seus processos de gestão também não investiram suficientemente em $T \& D$. 
Figura 3: Variáveis Preditoras e Não Preditoras das Estruturas

e Programas de T\&D

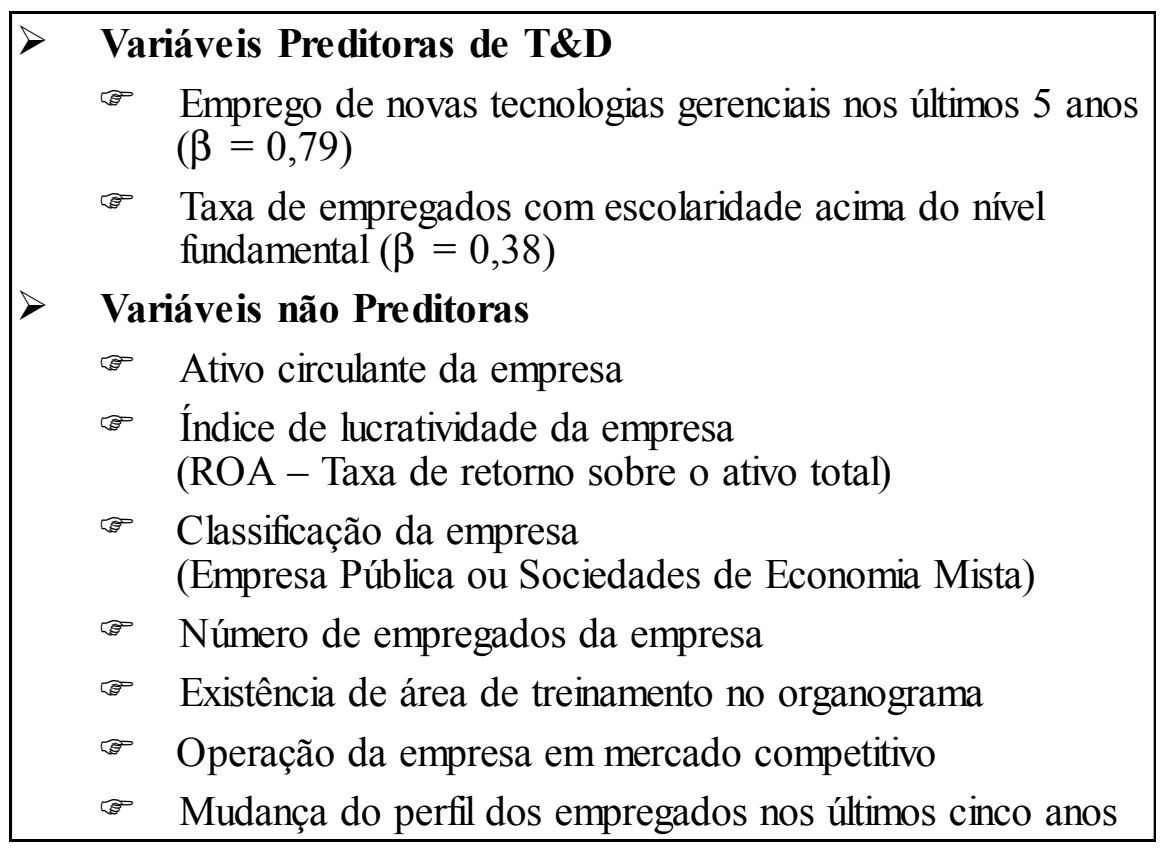

Fonte: dados da pesquisa.

A segunda variável explicativa relaciona a qualificação dos empregados às estruturas e programas de gestão. Empresas compostas de empregados com baixa escolaridade, que fazem atividades repetitivas ou manuais, não desenvolveram uma estrutura e programas de T\&D, ao contrário das empresas que possuem no seu negócio atividades que demandam um corpo técnico qualificado. Há, entretanto, em nossa amostra, empresas com quadro escolarizado e estrutura restrita de T\&D. Esta variável é explicativa somente em associação com a primeira.

Observando-se as variáveis não preditoras, obtiveram-se alguns resultados que vão de encontro a alguns mitos que se vulgarizaram sobre T\&D.

\section{Conclusóes e Propostas}

Embora a presente pesquisa não possa sustentar as proporções entre os grupos identificados pela escala de estrutura e programas de T\&D, quando se tenta 
generalizar os resultados para todas as empresas públicas e sociedades de economia mista do Estado de Minas Gerais, fica evidente para a equipe de pesquisadores que existem empresas com diferentes graus de organização e institucionalização dos seus esforços de qualificação profissional. Este dado, de per si, já nos permite contrapor certo jargão que se criou e se busca sustentar a golpes verbais contra as empresas públicas, resultado, entre outras coisas, de intensa propaganda vinculada a políticas de desestatização no segmento produtivo.

A estatística nos sugere que nas empresas em que se procurou implementar novas tecnologias de gestão e onde simultaneamente o perfil da escolaridade dos empregados é alto, houve todo um cuidado em se estruturarem áreas e programas de qualificação.

O casuísmo, intencional ou não, das políticas de privatização do Estado dificulta o planejamento e direcionamento dos programas de gestão das empresas públicas e sociedades de economia mista. Nas empresas onde o futuro é imprevisível, encontrou-se certo estado de suspensão administrativa, em que se mantém a máquina em funcionamento à espera de diretrizes, algumas vezes associado a um discurso de que não há privatização em vista. Este discurso é pouco convincente, porque nunca vem acompanhado de fatos que o justifiquem; é portanto uma esperança ou uma ardente fé.

Observando-se o conjunto dos programas e projetos das empresas naquilo que denominamos como sendo o grupo 3, conclui-se que elas não construíram as suas políticas e estrutura de qualificação apenas porque possuíam recursos, mas porque entreviam interesses organizacionais na constituição desta área. Neste segmento entende-se por que se encontrou um cluster tão expressivo de servidores na pesquisa da Fundação João Pinheiro (1996), que afirmava trabalhar em organizações com uma cultura de estruturação e planejamento.

Comparando-se os resultados obtidos com a pesquisa de Motta (1981), observam-se algumas modificações em T\&D das empresas públicas mineiras.

Nas empresas pesquisadas há quatro diferentes padrões de gestão de T\&D. O primeiro seria a ausência de área especializada, principalmente no grupo 1, e de programas estruturados, sendo a atividade realizada de forma marginal por um diretor ou gerente administrativo. O segundo seria a realização das atribuições próprias de $\mathrm{T} \& \mathrm{D}$ por um profissional generalista em recursos humanos, que realiza outras funções, como seleção, avaliação de desempenho etc. O terceiro é o que Motta (1981) identificou como típico na sua pesquisa, ou seja, uma área especializada dentro de recursos humanos. Um quarto padrão, ainda incipiente, encontrado em uma empresa, como possível alternativa ao anterior, é o da consultoria interna de T\&D como unidade de negócio da organização. Pode-se ainda 
falar de um quinto, não encontrado em nenhuma das empresas pesquisadas, que seria o das universidades corporativas que, por definição, são independentes da área de recursos humanos.

Nas empresas do grupo 2 e 3, encontramos quatro empresas que afirmam articular T\&D com o planejamento da organização, ou seja, houve avanço neste ponto com relação ao resultados da pesquisa de Motta (1981). Hoje, entretanto, discute-se o papel desta área na gestão estratégica da empresa, e o papel encontrado ainda é reativo. Neste mesmo grupo, houve avanços quanto à oferta de cursos, que não se apresentam mais como meros cardápios de curso a serem escolhidos, embora ainda exista esta prática. Nele os responsáveis por T\&D têm elaborado demandas específicas de cursos e identificado cursos no mercado que venham a solucionar problemas internos, não sendo correto considerá-los como “"centros de triagem' de demandas internas e ofertas externas", como Motta (1981) os havia qualificado na sua pesquisa. Ainda há, entretanto, áreas que se enquadram nesta descrição.

Na época, Motta (1981) afirmava que "na grande empresa pública federal encontram-se iniciativas de formação interna, acompanhadas de grandes centros de treinamento ou escolas". Na esfera estatal, vinte anos depois, encontram-se algumas iniciativas de formação interna (nos grupos 2 e 3 da pesquisa, obviamente), mas apenas um ou dois grandes centros de treinamento, os quais têm sido alvo de discussão quanto à sua continuidade dentro da organização.

A "pulverização de recursos evitando parcerias com universidades e centros de conhecimento", continua atual; encontramos alguma iniciativa neste sentido em duas das empresas pesquisadas, mas ainda incipientes. Mas há que se problematizar esta afirmativa, porquanto as universidades ainda não têm mostrado interesse na diversificação dos seus produtos, como, por exemplo, na oferta de cursos de curta duração, voltados ao cotidiano das empresas, que constituem uma necessidade prática a ser atendida pelas áreas de T\&D. Há também certo preconceito das duas partes em se encetarem propostas conjuntas de trabalho.

Outro ponto em que houve algum avanço diz respeito à afirmativa do autor que postulava que as áreas de T\&D "têm dificuldade em acompanhar as mudanças dos conhecimentos, tornando-se obsoletas e repetitivas". Com a consolidação de um mercado de pós-graduação lato sensu e os eventos no ambiente de negócios dos anos 90, verificamos o vínculo entre as empresas de melhor resultado em T\&D e a estruturação de áreas de T\&D, ou seja, T\&D tem algum papel, ainda que reativo, nos processos de mudança de conhecimentos dentro das empresas públicas em que tal se deu. 
A direção das áreas de T\&D na nossa amostra não tem preferência por um perfil de profissional, como encontrara Motta (1981), que questionava a direção por pedagogos e psicólogos. Encontramos profissionais de administração, psicologia, engenharia e economia na área, com uma incidência maior de administradores.

Os públicos não são exclusivamente do corpo gerencial, para programas de desenvolvimento gerencial, comuns na época da pesquisa de Motta (1981), havendo amplo acesso do corpo técnico, administrativo e operacional. Houve, entretanto, uma terceirização das atividades de apoio, e foram poucas as empresas que colocavam empregados terceirizados nas suas planilhas de treinamento.

Outra mudança significativa diz respeito ao "excesso de conteúdos psicológicos no treinamento gerencial", criticado por Motta (1981). A maior incidência de conteúdos, hoje, é da área de microinformática, por razões contingenciais, ao lado de treinamentos técnicos e de tecnologias gerenciais.

\section{Nota}

${ }^{1}$ Apoio: CNPq e FAPEMIG.

\section{ReferênCIAS Bibliográficas}

\section{AZEVEDO, S.;}

ANDRADE, L. A.

A reforma do Estado e a questão federalista : reflexões sobre a proposta Bresser Pereira. In: DINIZ, E.; AZEVEDO, S. Reforma do Estado e democracia no Brasil. Brasília : Editora da UnB, 1997.
BORGES-ANDRADE, J. E.

Avaliação de necessidades de treinamento : um método de análise de papel ocupacional. Tecnologia Educacional, ano XII, n. 54, set./out. 1983.

CÂMARA DA REFORMA DO ESTADO.

Plano diretor da reforma do aparelho do Estado. Brasília : MARE, 1995. 
CHINNAYYA, H. P. et al.

Training primary care health workers in mental health care : evaluation of attitudes towards mental illness before and after training. The International Journal of Social Psychiatry, v. 36, n. 4, p. 300-307, 1990.

CRUZ, M. V.;

QUEIROZ, J. A. DE F.;

SAMPAIO, J. DOS R.

Cultura organizacional : um estudo sobre a administração pública de Minas Gerais. In: SAMPAIO, J. (Org.). Psicologia do trabalho e gestão de recursos humanos : estudos contemporâneos. São Paulo : Casa do Psicólogo, 1998.

CURADO, I. B.;

PEREIRA FILHO, J. L.;

WOOD JR., T.

A gestão de recursos humanos na Grande São Paulo. São Paulo : Editora do SENAC, 1995.

DUTRA, M. L. S.

Avaliação de treinamento. Tecnologia Educacional, v. 13, n. 57, p. 14-26, mar./abr. 1984.

\section{EBOLI, M. P.}

Universidade corporativa : ameaça ou oportunidade para as escolas tradicionais de administração? Revista de Administração, v. 34, n. 4, p. 56-64, out./dez. 1999.
ERSKINE, J. A.;

LEENDERS, M.;

MAUFFETTE-LEENDERS, L.

Teaching with cases. Canada : School of Business Administration, 1981.

FISCHER, A. L.

A constituição do modelo competitivo de gestão de pessoas no Brasil : um estudo sobre as empresas consideradas exemplares. São Paulo : FEA/ USP, 1998.

FLEURY, A.;

FLEURY, M. T.

Aprendizagem e inovação organizacional : as experiências de Japão, Coréia e Brasil. São Paulo : Atlas, 1995.

FUNDAÇÃO JOÃO PINHEIRO.

A cultura organizacional nas instituições públicas do poder executivo do Estado de Minas Gerais. Belo Horizonte : FJP, 1996.

GARVIN, D.

Building a learning organization. Harvard Business Review, July/Aug. 1993.

GIL, A. C.

Como elaborar projetos de pesquisa. São Paulo : Atlas, 1987. 
GOULART, I. et al.

Movimentos emergentes na área de recursos humanos : a qualificação profissional. Belo Horizonte, FAPEMIG, 1999. relatório de pesquisa.

GOULART, I.;

SAMPAIO, J. (Org.).

Psicologia do trabalho e gestão de recursos humanos : estudos contemporâneos. São Paulo : Casa do Psicólogo, 1998.

GRYNA, F.

Treinamento para a qualidade. In: JURAN, J. M.; GRYNA, F. Controle de qualidade. Rio de Janeiro : Makron/ McGraw-Hill, 1992. v. 2.

HEINSELMAN, T.;

TATCH, L.

Executive coaching defined. Training and Development, $p$. 35-39, Mar. 1999.

JURAN, J. M.

Treinamento para a qualidade. In: Juran na liderança pela qualidade. São Paulo : Pioneira, 1990.

MALONE, S.

How to set up and manage a corporate learning centre. Hampshire, ENG : Gower Publisher, 1997.
MEISTER, J.

Educação corporativa : a gestão do capital intelectual através das universidades corporativas. São Paulo : Makron Books, 1999.

MINAS GERAIS.

Cadastro institucional dos órgãos e entidades da administração pública estadual do poder executivo. Belo Horizonte : SEPLAN, 1999.

MOTOMURA, O.

Jogos de empresa. In: BOOG, G. G. Manual de treinamento e desenvolvimento. São Paulo : McGraw-Hill, 1980.

MOTTA, P. R.

Treinamento e desenvolvimento gerencial : inferências sobre a experiência das empresas estatais no Brasil. Revista de Administração Pública, v. 15, n. 1, p. 124133, jan./mar. 1981.

RABELO, F. M.;

BRESCIANI FILHO, E.;

OLIVEIRA, C. A. B.

Treinamento e gestão da qualidade. Revista de Administração de Empresas, v. 35, n. 3, p. 1319, maio/jun. 1995.

RAMOS, C.

Simulações e jogos : formação e treinamento de administradores. Brasília : ENAP, 1991. 
ROBBINS, S.

Comportamento organizacional. 8. ed. São Paulo : LTC, 1999.

RODRIGUES, J. L.;

ACHCAR, I.

Reconversão profissional : conceitos e propostas. Em Aberto, v. 15, n. 65 , p. $118-135$, jan./mar. 1995.

SAMPAIO, J. DOS R.

Nipo-brasileiros : um estudo sobre a gestão de recursos humanos de empresas industriais japonesas situadas no Brasil. Belo Horizonte, 1995. Dissertação (Mestrado em Administração) Centro de Pós-Graduação e Pesquisa em Administração, Universidade Federal de Minas Gerais.

(Org.). Qualidade de vida, saúde mental e psicologia social : estudos contemporâneos II. São Paulo : Casa do Psicólogo, 1999.
SAUAIA, A. C. A.

Jogos de empresas : aprendizagem com satisfação. Revista de Administração, v. 32, n. 3, p. 1327, jul./set. 1997.

SENGE, $\mathrm{P}$.

A quinta disciplina. 14. ed. São Paulo : Best-Seller, 1990.

TACH, L.;

HEINSELMAN, T.

Executive coaching defined. Training and Development, $p$. 34-39, Mar. 1999.

VARGAS, M. R. M.

Treinamento e desenvolvimento : reflexões sobre seus métodos. Revista de Administração, v. 31, n. 2, p. 126-136, abr.jun. 1996.

VENEU, M. G.

Representações do funcionário público. Revista de Administração Pública, v. 24, n. 1, p. 516, nov. 1989/jan. 1990. 